\title{
Effect of Hibiscus sabdariffa calyx extract on reproductive hormones in normal rats
}

\author{
Nizar Sirag ${ }^{1}$, Elhadi M. Ahmed ${ }^{1}$, Algaili M. Algaili ${ }^{2}$ Hozeifa Mohamed ${ }^{3 \star}$ and Imad M. Tajeldeen ${ }^{3}$ \\ ${ }^{1}$ Department of Pharmacognosy, Faculty of Pharmacy, University of Gezira, Sudan. \\ ${ }^{2}$ Department of Pathology, Faculty of Medicine, University of Gezira, Sudan. \\ ${ }^{3}$ Department of Pharmacology, Faculty of Pharmacy, University of Gezira, Sudan.
}

Accepted 12 August, 2013

\begin{abstract}
Medicinal plants contain physiologically active principles that over the years had been exploited in traditional medicine for the treatment of various ailments. The present study was undertaken to investigate the effects of ethanolic extract of Hibiscus sabdariffa calyx on rat reproductive hormones. The effects on the basal levels of estradiol, testosterone, prolactin and follicle stimulating hormone were conducted in experimental animals. $H$. sabdariffa calyx extract at a dose of $250 \mathrm{mg} / \mathrm{kg}$ produced minor effects on rat reproductive hormones, namely testosterone and estradiol while no change was observed on both prolactin and follicle stimulating hormone levels. Moreover, no histological changes were detected on both testes and ovaries of the experimental animals after 28 days of administration. It can be concluded that $H$. sabdariffa calyx extract at a dose of $250 \mathrm{mg} / \mathrm{kg}$ caused mild effects on rat reproductive hormones.
\end{abstract}

Key words: Estrogenic effect, reproductive hormones, Hibiscus sabdariffa extract.

\section{INTRODUCTION}

Endocrine disrupting compounds (EDCs) are natural or synthetic compounds that have the ability within the body to alter endocrine functions often through mimicking or blocking endogenous hormones (James et al., 2013). These actions on the endocrine system have resulted in developmental deficits in various invertebrate and aquatic species (Crain et al., 2007; Elango et al., 2006) and mammals (Christopher et al., 2012). Exposures in adulthood have consequences but fetal and early life exposures appear to have more severe effects that persist through life (Rubin and Soto, 2009). Among these classes of chemicals are phytoestrogens that show effects suggestive of estrogenicity, such as binding to the estrogen receptors, induction of specific estrogen- responsive gene products, stimulation of estrogen receptor(s) and positive breast cancer cell growth (James et al., 2013). Through these interactions by acting as agonists or antagonists, EDCs are able to alter the activity of response elements of genes, block natural hormones from binding to their receptors, or in some cases increase the perceived amount of endogenous hormone in the body by acting as a hormone mimic to its receptor (Ze-hua et al., 2010).

Hibiscus sabdariffa Linn (Roselle) is an annual shrub commonly used to make jellies, jams and beverages. The brilliant red colour of its calyx makes it a valuable food product, a part from its multitude of traditional medicinal uses. Infusions of the calyces are considered as diuretic,

*Corresponding author. E-mail: hozhooz@hotmail.com. 
cholerectic, febrifugal and hypotensive, decreasing the viscosity of the blood and stimulating intestinal peristalsis (Salleh et al., 2002). Roselle calyx extract is a good source of antioxidants from its anthocyanins and associated with antitumor and inhibitory effects on the growth of several cancer cells (Ajiboye et al., 2011).

Extracts of $H$. sabdariffa calyces have been reported to be rich in phytoestrogens (Adigun et al., 2006; Orisakwe et al., 2004; Brian et al., 2009; Omotuyi et al., 2011) and some reports indicated that $H$. sabdariffa calyces have estrogenic effects, although exact estrogen-like ingredient is not determined (Ali et al., 1989). This study was undertaken to determine to which extent $H$. sabdariffa calyces extract alters the basal levels of selected reproductive hormones: estradiol, testosterone, prolactin and follicle stimulating hormone as well as the histological features of both testes and ovaries of rats.

\section{MATERIALS AND METHODS}

\section{Plants}

The dried calyces of $H$. sabdariffa were purchased from the local market in Wad-Medani, Sudan. The plant material was identified by the Department of Pharmacognosy, Faculty of Pharmacy, University of Gezira, Sudan.

\section{Extraction of plant material}

One hundred grams of coarsely powdered calyces of $H$. sabdariffa were extracted by maceration using ethanol $(70 \%)$ in a conical flask for $72 \mathrm{~h}$, kept away from light throughout the extraction period, then filtered and evaporated by a rotary evaporator at $60^{\circ} \mathrm{C}$. The resulting solution was freeze dried and placed into a refrigerator until use.

\section{Effect of ethanolic extract of Hibiscus sabdariffa calyx on rat} reproductive hormones

\section{Experimental animals}

The effect of ethanolic extract of $H$. sabdariffa calyx on rat reproductive hormones was conducted based on the method described by Omotuyi et al. (2011). A total of 20 rats (10 each for males and females) were housed in a clean animal house subjected to an intensive nutritional program. Rats were acclimatized for a period of 14 days under standard environmental conditions. The ethical committees, University of Gezira and Ministry of Health, Gezira State, ethically approved the experimental protocol.

\section{Experimental design}

Albino wistar rats were divided into four groups each of five. Water control groups for both males and females and the other two groups (either males or females) received $250 \mathrm{mg} / \mathrm{kg}$ of plant extract via gastric tube daily for 28 days.

\section{Collection of blood samples}

Blood samples were collected from conjunctival veins using capillary tubes at 7-day intervals for 28 days.

\section{Hormonal assay}

The hormones were estimated using the standard protocols of enzyme-linked immunosorbent assay (ELISA) kits (Roche, Switzerland) for determination of estradiol, testosterone, prolactin and follicle stimulating hormone (FSH) levels.

\section{Histopathological examination}

Twenty-eight days after oral administration of the extract, all experimental animals were anaesthetized using chloroform vapour and dissected. The ovaries and testes were collected and immediately fixed in Bouins fluid for $6 \mathrm{~h}$ and transferred to $70 \%$ alcohol for histological processing according to Drunny and Wallington (1990). Briefly, following fixation of the right side testes and ovaries from both control and test animals, tissue sections were processed by dehydration in $95 \%$ and absolute alcohol, cleared in xylene and embedded in pure clean moltenparaffin wax from which blocks of tissues were made for sectioning. Ribbon slices of about $5.0 \mu \mathrm{m}$ in thickness were made with the aid of a microtome (delete machine) and the sections picked with slides, which were dried in oven. The slices were stained with haemotoxylin and eosin, and then mounted using DPX onto a light microscope (delete magnification $40 \times$ for testes and $10 \times$ for ovary) for histopathological and morphological changes.

\section{Data analysis}

All the obtained data were expressed as means \pm standard deviation and analyzed using analysis of variance (ANOVA). Comparisons with the control groups were made using One-way ANOVA. Differences were considered significant if $P$-value $<0.05$.

\section{RESULTS}

\section{Effect of ethanolic extract of $\boldsymbol{H}$. sabdariffa calyx on estradiol levels in female rats}

The study revealed that the ethanolic extract of $H$. sabdariffa calyx in a dose of $250 \mathrm{mg} / \mathrm{kg}$ exhibited a mild increase ( $p$-value $<0.05$ ) in estradiol level in female rats in time-dependent manner (Table 1). On day 28, estradiol reached more than twice the value observed on day 0 compared to those of water control group.

\section{Effect of ethanolic extract of $\boldsymbol{H}$. sabdariffa calyx on testosterone levels in male rats}

Following intragastric administration of $250 \mathrm{mg} / \mathrm{kg}$ of ethanolic $H$. sabdariffa calyx extract for 28 days, serum levels of testosterone were significantly reduced ( $\mathrm{P}$-value 
Table 1. Serum estradiol levels $(\mathrm{pg} / \mathrm{ml})$ in female rats $(n=5)$ after oral administration of ethanolic extract of Hibiscus sabdariffa calyx and water (SD \pm SEM).

\begin{tabular}{lccccc}
\hline Preparation & Day 0 & Day 7 & Day 14 & Day 21 & Day 28 \\
\hline Hibiscus sabdariffa & $6.40 \pm 29$ & $8.12 \pm 39$ & $12.93 \pm 40$ & $15.92 \pm 47$ & $16.6 \pm 50$ \\
Control (water) & $5.39 \pm 30$ & $6.1 \pm 35$ & $6.14 \pm 34$ & $6.34 \pm 36$ & $7.12 \pm 37$ \\
\hline
\end{tabular}

*P-value $<0.05$

Table 2. Serum testosterone levels $(\mathrm{ng} / \mathrm{ml})$ in male rats $(n=5)$ after oral administration of ethanolic extract of Hibiscus sabdariffa calyx and water (SD \pm SEM).

\begin{tabular}{lccccc}
\hline Preparation & Day 0 & Day 7 & Day 14 & Day 21 & Day 28 \\
\hline Hibiscus sabdariffa & $2.77 \pm 3.66$ & $2.18 \pm 1.89$ & $1.44 \pm 1.02$ & $0.8 \pm 0.53$ & $0.54 \pm 0.16$ \\
Control (water) & $0.47 \pm 2.64$ & $0.68 \pm 2.37$ & $0.94 \pm 0.64$ & $1.34 \pm 1.06$ & $1.07 \pm 2.39$ \\
\hline
\end{tabular}

${ }^{*}$ P-value $<0.05$

$<0.05)$ in male rats throughout the experimental period compared to those of water control group (Table 2).

\section{Effect of ethanolic extract of $\boldsymbol{H}$. sabdariffa calyx on prolactin and $\mathrm{FSH}$ levels in female rats}

The ethanolic extract of $H$. sabdariffa calyx in a dose of $250 \mathrm{mg} / \mathrm{kg} / \mathrm{ml}$ did not cause changes in the serum levels of prolactin or FSH throughout the experimental period in female rats administered the plant extract for 28 days.

\section{Histological effects of $\boldsymbol{H}$. sabdariffa calyx extract on rat testes and ovaries}

The extract did not cause histological changes on both testes and ovaries of the experimental animals when the plant extract was administered for 28 days.

\section{DISCUSSION}

Certain phytoestrogens such as isoflavones and lignans have been thoroughly investigated for their estrogenic properties (Miksicek, 1995; Collins et al., 1997; So et al., 1997). Extracts of $H$. sabdariffa have been reported to be rich in phytoestrogen (Adigun et al., 2006; Orisakwe et al., 2004; Brian et al., 2009; Omotuyi et al., 2011). There are reports indicated that $H$. sabdariffa calyces have estrogenic effects, although exact estrogen-like ingredient is not determined (Ali et al., 1989). Moreover, plant phenols, anthocyanin isolates and anthocyanin-rich mixture of bioflavonoids possess estrogenic activities (Omotuyi et al., 2011).
The reduction of serum level of testosterone in male rats produced by ethanolic extract of $H$. sabdariffa calyx may be explained by the estrogenic activity of the plant, an evidence raised by Orisakwe et al. (2004). Furthermore, other studies had reported a statically significant decrease in testosterone levels in laboratory animals treated with phytoestrogens (Sharpe et al., 2002; Cline et al., 2004). The precise role that oestrogens play in male reproductive development is unclear, but generally, oestrogens tend to have 'demasculinising' or antiandrogenic effects. In foetal and neonatal life, this probably results from suppression of testosterone production (Haavisto et al., 2001), or loss of androgen receptors (McKinnell et al., 2001). Oestrogens are synthesised from androgens via the action of a single enzyme (aromatase), and there is a close relationship between the actions of these two hormones. Moreover, testosterone may be converted to estrogen by aromatase (Benassayag et al., 2002).

Although dietary phytoestrogens have been implicated in adverse effect upon fertility in various animals, there are few published reports of such effects in human populations consuming large amounts of these substances (Benassayag et al., 2002). In male rats, reduction of testosterone level might impair spermatogenesis and cause male infertility (Orisakwe et al., 2004). It should be noted that in the study of herbal extracts, one could not attribute the observed biological effects to a particular constituents because many other compounds are present in the plant extracts (Saied-Karblay et al., 2010). Factors such as species, age, gender, diet, dose, route of administration and metabolism strongly influence the ultimate biological response to phytoestrogen exposure (Shweta, 2009). 


\section{Conclusion}

$H$. sabdariffa calyx extract caused mild effects on rat reproductive hormones and due to the pleiotropic effects of phytoestrogens in vivo, a broad panel of in vitro assays covering not only estrogenic action but also other regulating processes has to be used to assess the potential of plant-derived compounds to beneficially or adversely affect human health.

\section{REFERENCES}

Adigun MO, Ogundipe OD, Anetor JI, Detunde AO (2006). Dosedependent changes in some haematological parameters during shortterm administration of Hibiscus sabdariffa aqueous extract (zobo) in wistar albino rats. Afr. J. Med. Med. Sci. 35:73-77.

Ajiboye TO, Salawu NA, Yakubu MY, Oladiji AT (2011). Antioxidant and drug detoxification potentials of Hibiscus sabdariffa anthocyanin extract. J. Drugs Chem. Toxicol. 34:109-115.

Ali MS, Salih WM, Humida AM (1989). An estrogenic-like activity of Hibiscus sabdariffa. Fitoterapia. 60:547-548.

Benassayag C, Perrot-Applanat M, Ferre F (2002). Phytoestrogens as modulators of steroid action in target cells. J. Chromatogr. B. 777:233-248.

Brian J, Jonna F, Lauren E, Alice P, Gail B (2009). Estrogenic effects of herbal medicines from Costa Rica used for the management of menopausal symptoms. J. Menopause, 16 (4):748-755.

Christopher R, Cederroth 1; Céline 1 and Serge, A (2012). Soy, phytoestrogens and their impact on reproductive health. Mol. Cell. Endocrinol. 355:192-200

Cline JM, Franke AA, Register TC, Adams MR (2004). Effects of dietary isoflavones aglycones on the reproductive tract of male and female mice. J. Toxicol. Pathol. 32:91-99.

Collins BM, Mclachlan JA, Arnold SF (1997). The estrogenic and antiestrogenic activities of phytochemicals with the human estrogen receptor expressed in yeast. Steroids. 62:365-372.

Crain DA, Eriksen M, Iguchi T, Jobling S, Laufer H (2007). An ecological assessment of bisphenol-A: evidence from comparative biology. J.I Reprod. Toxicol. 24:225-239.

Drunny RAB, Wallington EA (1990). Histological Techniques 5th Ed London, Oxford University Press, pp 199-220.

Elango A, Shepherd B, Chen TT (2006). Effects of endocrine disrupters on the expression of growth hormone and prolactin mRNA in the rainbow trout pituitary. J. Gen. Comp. Endocrinol.145:116-127.

Haavisto T, Numela K, Pohjanvirta R, Huuskonen J (2001). Prenatal testosterone and LH levels in male rats exposed during pregnancy to 2,3,7,8-tetrachlorodibenzo-p-dixin and diethylstilbestrol. J. Mol. Cell Endocrinol.178:169-179.
James A, Rogers L, Metz V, Wee Y (2013). Review: Endocrine disrupting chemicals and immune responses: A focus on bisphenol-A and its potential mechanisms. J. Mol. Immunol. 53:421-430

McKinnell C, Atanassova N, Williams K, Fisher JS, Walker M, Turner KJ, Saunders, PTK, Sharpe RM (2001). Suppression of androgen action and the induction of gross abnormalities of the reproductive tract in male rats treated neonatally with diethylstilbestrol. J. Androl. 22:323-338.

Miksicek RJ (1995). Estrogenic flavonoids: structural requirements for biological activity. Proc. Soc. Exp. Biol. Med. 208:44-50.

Omotuyi IO, Ologundudu A, Onwubiko VO, Wogu MD (2011). Hibiscus sabdariffa Linn anthocyanins alter circulating reproductive hormones in rabbits. J. Diabetes Endocrinol. 1(3):36-45.

Orisakwe OE, Husaini DC, Afonne OJ (2004). Testicular effects of subchronic administration of Hibiscus sabdariffa aqueous extract in rats. J. Reprod. Toxicol.18:295-298.

Rubin BS, Soto AM (2009). Bisphenol A: perinatal exposure and body weight. J. Mol. Cell. Endocrinol. 304:55-62.

Saied-Karbalay D, Ali N, Farzaneh D, Mohammad R (2010). Effects of hydroalcoholic extracts of Matricaria chamomilla on serum testosterone and estradiol levels, spermatozoon quality and tail length in rat. Iran J. Med. Sci. 35(2):25-32.

Salleh N, Runnie I, Roach D, Mohamed S, Abeywardena Y (2002). Inhibition of low-density lipoprotein oxidation and up-regulation of low-density lipoprotein receptor in HepG2 cells by tropical plant extracts. J. Agric. Food Chem. 50:3693-3697.

Sharpe RM, Martin B, Morris K, Walker M (2002). Infant feeding with soy formula: effects on the testis and blood testosterone levels in marmoset monkeys during the period of neonatal testicular activity. J. Human Reprod. 17(7):1692-1703.

Shweta T, Bhavana B, Aditi D, Durgesh N (2009). Effect of Carum carvi and Curcuma longa on hormonal and reproductive parameter of female rats. Int. J. Phytomed. 1:31-38.

So FV, Guthrie N, Chambers AF, Carroll KK (1997). Inhibition of proliferation of estrogen receptor-positive MCF-7 human breast cancer cells by flavonoids in the presence and absence of excess estrogen. Cancer Lett. 112:127-133.

Ze-hua L, Yoshinori K, Satoshi M (2010). A review of phytoestrogens: Their occurrence and fate in the environment. Water Res. 44:567577. 